\title{
ENTENDENDO OS CONFLITOS NO CONTEXTO DO TRABALHO COLETIVO SOB OS PRINCÍPIOS DA ECONOMIA POPULAR E SOLIDÁRIA
}

\author{
SANTOS, Liziany Cerqueira ${ }^{1}$; PITA, Flávia Almeida ${ }^{2}$ \\ 1. Bolsista PIBIC/Fapesb, Graduanda em Direito, Universidade Estadual de Feira de Santana, e-mail: \\ lizianycs@gmail.com \\ 2. Orientadora, DCIS, Universidade Estadual de Feira de Santana, \\ e-mail: fa-pita@uol.com.br
}

PALAVRAS-CHAVE: economia popular e solidária; autogestão; mediação.

\section{INTRODUÇÃO}

A Economia Solidária ganhou espaço nas últimas décadas em decorrência de um declínio do capitalismo provocado pelas crises que este sistema vivencia e o consequente crescimento do desemprego, do trabalho precário e informal, além dos constantes ataques aos direitos sociais e trabalhistas.

O mito da meritocracia transforma indivíduos hipossuficientes em referentes ausentes. Ou seja, os donos do capital, que exploram trabalhadores, vendem a ideia de que estes podem tornar-se patrões, desde que deem o "melhor de si". Os referenciais (trabalhadores) se tornam menos ameaçadores à medida que compram essa mentira $\mathrm{e}$ trabalham de forma individualista, competindo entre si. Ao priorizarem apenas o "sucesso" pessoal, vão se tornando invisíveis (ausentes).

Para Paul Singer (2013), a cooperação em detrimento da competição entre os participantes de qualquer atividade econômica é pressuposto essencial para que uma sociedade possa deixar de ser considerada desigual.

Não nos faltam exemplos ao longo da história de agrupamentos de indivíduos que lutaram em prol de uma causa em comum e se reconheceram mais fortes enquanto coletivo, ameaçando o status quo. Sejam os núcleos de resistência contra a Alemanha nazista, os negros que não aceitavam ser subjugados pela escravidão ou as feministas subversivas.

Assim, configura-se uma etapa importante para a consolidação do trabalho cooperativo a pacificação dos conflitos entre os membros de um grupo informal composto por mulheres socialmente vulneráveis - a Cooperativa Mãos Solidárias (Coopermasol), que atua na produção e comercialização de lanches em uma das cantinas da Universidade e recebe acompanhamento, desde 2008, da Incubadora de Iniciativas da Economia Popular e Solidária da Universidade Estadual de Feira de Santana (IEPS-UEFS).

Importante destacar que no curso desta pesquisa foram incorporados elementos novos a serem estudados, como o acompanhamento de outro grupo também em processo de incubação - ao qual também foi cedido um espaço pedagógico dentro da Universidade. Foi possível acompanhar o surgimento de conflitos entre os dois grupos, criando uma aparente rivalidade. No entanto, para além da rivalidade intergrupos, observou-se que as trabalhadoras do segundo grupo não se adaptaram ao trabalho cooperado e passaram a adotar condutas que fugiam abertamente dos propósitos da Economia Popular e Solidária, resultando no término precoce do processo de incubação.

Dessa forma, não foi possível desenvolver a pesquisa no sentido do tratamento de eventuais conflitos existentes entre os dois grupos mencionados.

Por fim, acredita-se que uma decisão judicial imposta pelo Estado nem sempre é capaz de satisfazer e conciliar as partes a fim de que tenham condições de dar continuidade a realização de um trabalho coletivo - restaurando a horizontalidade das relações. Este é um processo que se confirma quando há disposição de ambos os lados 
envolvidos no conflito, o qual pode ser um obstáculo intransponível e levar ao rompimento da relação ou surgir como um elemento capaz de levar as pessoas envolvidas a um estágio mais elevado de empatia e compreensão para com a outra.

\section{MATERIAL E MÉTODOS OU METODOLOGIA (ou equivalente)}

Foram levantados materiais bibliográficos, produzidos relatórios a partir de visitas feitas ao grupo Coopermasol e ao grupo Sabores, na tentativa de identificar as questões que mais são objetos de controvérsias e elaborada oficina com conteúdo didático e ao mesmo tempo lúdico, propiciando aos cooperados e cooperadas ferramentas para que desconstruam os conflitos por conta própria.

Posteriormente, intencionou-se compartilhar a pesquisa teórica através de cursos e oficinas com as trabalhadoras a fim de estas se familiarizem com os pressupostos e ideais cooperativistas, das relações solidárias e estejam aptos a participar e contribuir em discussões relacionadas à forma de lidar com os conflitos entre os membros dos grupos.

A pesquisa também demandou a realização de entrevistas com o objetivo de levantar informações sobre a convivência dos grupos, o nível de conhecimento sobre seus direitos e deveres e o perfil e interesses de cada um a fim de identificar os motivos e as consequências dos conflitos ocorridos até então, para que seja possível construir, coletivamente, a identidade de cada grupo.

Feito o diagnóstico, pretendia-se realizar reuniões destinadas a ouvir os membros dos grupos sobre quais seriam as possíveis soluções para os conflitos apresentados. A partir disso serão pensadas as ações de conciliação e mediação.

A aplicação dos métodos alternativos de resolução de conflitos terá como objetivo avaliar sua eficácia enquanto facilitadora do acesso à justiça.

Ainda por meio da pesquisa, pretendia-se definir ações no sentido de informar e assessorar o grupo no caminho de sua formalização jurídica.

As reuniões, cursos e oficinas foram idealizados no espaço da Incubadora e os materiais necessários serão canetas, blocos de anotações, folhas de papel ofício, entre outros.

\section{RESULTADOS E/OU DISCUSSÃO (ou Análise e discussão dos resultados)}

Um contato superficial com os pressupostos e princípios da Economia Popular e Solidária pode nos guiar pelo caminho ilusório de supor que trabalhar com uma perspectiva totalmente oposta à lógica predatória e desumana do capitalismo significa lidar apenas com pessoas dispostas a construir relações harmônicas e horizontais - em que todos os lados da equação se apoiem mutuamente na construção de um mundo melhor para todos e todas.

$\mathrm{O}$ aprofundamento teórico aliado ao contato direto com a realidade de pessoas que lutam diariamente para sobreviver nesse sistema que marginaliza, discrimina e exclui, nos retira desse estado de deslumbramento inicial e nos força a fazer autoavaliações, no sentido de compreender qual o seu papel, enquanto pesquisador e integrante daquela realidade, no objetivo comum de transformá-la e construir um mundo menos desigual e cruel.

Os indivíduos, com toda sua complexidade e pluralidade de entendimentos, medos, sonhos e visões do mundo, são majoritariamente socializados para aceitar e adaptar-se a um modo de vida que identifique o outro (o negro, judeu, homossexual, a mulher, os transexuais, o idoso, o "louco", o pobre, os animais) como diferente. E, por algo ser alheio daquilo que se é, não deve ser detentor dos mesmos direitos, mas destituído do seu valor. 
Enxergar nos conflitos a sua potencialidade transformadora, bem como reconhecer que são naturais e acontecem em qualquer situação que envolva mais de uma pessoa, foi uma etapa crucial nesse processo, que não teria sido alcançada sem a ajuda mútua entre pesquisadores e integrantes dos grupos. Nada é estanque quando se trata do ser humano, estamos em processo de mutação, aperfeiçoamento e evolução a todo instante, o que significa dizer que é possível desconstruir preconceitos, assim como aprender (ou reaprender) a ser solidário, ter empatia pelo outro.

O estudo dos conflitos gerados a partir da interação entre mulheres da Coopermasol demonstrou que o grupo criou uma aparente rivalidade entre as cooperadas que trabalham pela manhã e as que trabalham pela tarde na cantina. Houve ruptura na comunicação e a confiança foi fragilizada - fazendo com que as trabalhadoras adotassem posturas individualistas (que puderam ser constatadas a partir das entrevistas e das visitas feitas ao grupo) como, por exemplo, deixar o ambiente sujo para que quem assuma o próximo turno faça a limpeza.

Após esse período de estranhamento que, ressalte-se, foi o primeiro apenas do ponto de vista dessa pesquisa, um dos resultados observados foi a saída de 06 (seis) das 10 (dez) pessoas que integravam o grupo, de modo que hoje a Coopermasol é composta por 04 (quatro) mulheres.

Disso pode-se tirar tanto uma avaliação positiva quanto uma negativa. Positiva no sentido de que os conflitos oriundos da desconfiança, de uma comunicação cada vez mais deficiente, fez com que essas 06 (seis) pessoas que saíram se desacomodassem e buscassem a mudança, pois a roupagem do trabalho coletivo naquele contexto não lhes cabia mais. Por outro lado, observando o grupo sob outras lentes seria razoável dizer que as pessoas que ficaram se dividem entre duas que dominam a comunicação e manipulam as decisões do grupo, enquanto as outras duas se submetem pela necessidade do trabalho. Não sem questionar, é verdade, pois durante as visitas e reuniões foram documentadas uma série de reclamações com relação a essas duas pessoas que estariam exercendo uma função de "liderança".

As pessoas tem tendência a formar grupos com a sua própria cultura, limites e círculos de afinidade definidos - o que leva a um fácil envolvimento em conflitos quando "confrontados" com grupos distintos. Os psicólogos que realizaram o estudo e provocaram os conflitos entre os grupos experimentados podem ser comparados ao sistema capitalista. O capitalismo sobrevive da competição e se fortalece quando um grupo consegue superar as dificuldades sem a ajuda do outro, pois o individualismo e a desigualdade são a essência deste sistema.

No caso da Coopermasol, nota-se que o desentendimento entre as cooperadas é decorrente de atitudes que prejudicam ou afetam o interesse, a necessidade ou valores do outro membro do grupo. É o que se pode observar, por exemplo, numa conversa com uma das trabalhadoras em que ela exterioriza a sua insatisfação com o fato de que certas cooperadas não agem de acordo com o que ela chama de "espírito de grupo"1, pois, segundo ela, algumas se sentem como se fossem "chefe" da cooperativa e no direito de maltratar as demais.

É importante ressaltar que durante esta pesquisa, houveram modificações com relação aos grupos acompanhados, tendo em vista que o processo de Incubação do Grupo Sabores foi interrompido por conta da não observância dos princípios da Economia Popular e Solidária. Não obstante, em março deste ano foi iniciado o período de pré-incubação do grupo Sabores do Quilombo, o qual assumiu a cantina do Módulo I da Universidade e atualmente fornece alimentação com produtos provenientes de uma

\footnotetext{
${ }^{1}$ Esse espírito de grupo certamente faz referência aos princípios que regem a economia solidária, ou seja, a solidariedade, a cooperação e a autogestão. Isto representa a eficácia do processo de incubação no sentido de educar pessoas para o trabalho numa perspectiva solidária.
} 
comunidade quilombola localizada em Lagoa Grande, no Distrito de Maria Quitéria. Dessa forma, não houve ação específica quanto à resolução de conflitos, pois o grupo encontra-se numa fase de adaptação ao trabalho coletivo e solidário, debruçando-se sobre questões mais urgentes como a divisão e a organização dos trabalhos, das sobras.

\section{CONSIDERAÇÕES FINAIS (ou Conclusão)}

O desejo de contribuir para a superação do que hoje constitui um obstáculo ao desenvolvimento da Coopermasol ensejou o estudo de mecanismos extrajudiciais (em especial a mediação) para tratamento das controvérsias apresentadas pelos membros do grupo.

Considerando a importância que o princípio da autogestão assume no contexto da Economia Popular e Solidária, foi imprescindível que as cooperadas constatassem a possibilidade e a importância de que a pacificação dos conflitos seja realizada por elas próprias.

Não obstante, foi preciso desmistificar a percepção do conflito como algo inteiramente negativo, tendo em vista que este é uma consequência inevitável das relações humanas, em qualquer contexto. Diante disso, somos colocados diante da possiblidade de canalizar a energia gasta nos esforços para exterminar o conflito e direcioná-la para o enfrentamento ao processo de exclusão social e das práticas exploratórias promovidas pelo sistema capitalista e patriarcal em detrimento das camadas mais vulneráveis da sociedade.

Ao longo da pesquisa e das ações desenvolvidas foi possível constatar que a utilização de técnicas de mediação apresenta grande identidade com os ideais da Economia Popular e Solidária, cedendo horizontalidade à pacificação dos conflitos, visto que os pessoas não se enfrentam para solucionar os litígios, mas, sim, se solidarizam, ouvindo um ao outro, reconhecendo o problema e buscando um desfecho que satisfaça os interesses de todas os envolvidos.

\section{REFERÊNCIAS}

BEZERRA, Tássio. A mediação enquanto instrumento de emancipação da cidadania e de democratização da justiça e do direito; Revista Direito e Sensibilidade, $1^{\text {a }}$ ed., 2011;

BRANDÃO, Carlos Henrique. A pesquisa participante: um momento da educação popular. Revista Educação Popular, Uberlândia, v. 6, p.51-62. jan./dez. 2007;

ENGELS, Friedrich. A Origem da família, da Propriedade privada e do Estado. São Paulo: Nosso Livro, 1984;

Incubadora de Iniciativas da Economia Popular e Solidária da Universidade Estadual de Feira de Santana - IEPS/UEFS. Carta de Princípios. Feira de Santana, BA, 2011;

MORAIS, José Luis Bolzan de; SPENGLER, Fabiana Marion. Mediação e Arbitragem: Alternativas à jurisdição. Porto Alegre: Livraria do Advogado, 2008;

ORWELL, George. A Revolução dos Bichos. São Paulo: Companhia das Letras, 1945;

REBOUÇAS, Gabriela Maia. Tramas entre Subjetividades e Direito: A Constituição do Sujeito em Michel Foucault e os Sistemas de Resolução de Conflitos. Recife: Lumen Juris, 2010;

ROUSSEAU, Jean-Jacques. Do Contrato Social. Porto Alegre: L\&PM, 2014;

SINGER, Paul. Introdução à Economia Solidária. São Paulo: Fundação Perseu Abramo, $1^{\text {a }}$ ed., 2013; 